\title{
US FDA Clinical Endpoint BE Studies v1.0
}

National Cancer Institute

\section{Source}

National Cancer Institute. US FDA Clinical Endpoint BE Studies v1.0. NCI Thesaurus. Code C161475.

The 1.0 version of the FDA Clinical Endpoint BE Studies Technical Specifications Guidance. 